\title{
In situ Characterization of Redox Process in Ceria and Ceria-Zirconia
}

\author{
Ruigang Wang, ${ }^{*}$ Peter A Crozier, Renu Sharma, ${ }^{*}$ and James Adams ${ }^{* *}$ \\ * Center for Solid State Science, Arizona State University, Tempe, AZ 85287-1704 \\ ** Chemical and Materials Engineering, Arizona State University, Tempe, AZ 85287-1704
}

Cerium based catalysts play an important role in the emissions control from mobile sources. The low-temperature reducibility of ceria and ceria-zirconia is very important and is strongly influenced by prior heat treatments. Characterization of ceria-based catalysts during redox cycles is essential to understand their buffer function for oxygen storage and release. Photo-absorption spectra [1] (XAS, $\mathrm{M}_{4,5}$ white line), X-ray photoemission spectra [1] (XPS, $3 \mathrm{~d}_{3 / 2}$ and $3 \mathrm{~d}_{5 / 2}$ ) and electron energy loss spectra [2] (EELS, M $\mathrm{M}_{4,5}$ white line) are usually used to quantify the oxidation or valence state of Ce $\left(\mathrm{Ce}^{4+} / \mathrm{Ce}^{3+}\right)$. However the redox behavior of $\mathrm{Ce}$ is difficult to quantify, as partially reduced cerium oxide is unstable at low temperatures and/or high oxygen partial pressure. For this reason, we have undertaken a detailed in situ TEM study of the dynamic nanostructural and nanochemical changes that take place in ceria and ceria zirconia during the redox cycles.

High surface area catalyst samples of ceria and ceria-zirconia were synthesized using coprecipitation techniques [3] and in situ nanocharacterization was performed in an environmental transmission electron microscopy (ETEM) Tecnai F20, operated at 200KV and equipped with a Gatan imaging filter (GIF) and annular dark-field detector [4]. Ceria powder was dispersed over Pt grids and loaded into the microscope using a furnace-heating holder. The samples were heated progressively up to $700^{\circ} \mathrm{C}$ in dry 0.5 Torr of $25 \% \mathrm{H}_{2} / 75 \% \mathrm{~N}_{2}$ mixture. Time and temperature resolved high resolution electron microscopy (HREM) images and electron energy-loss spectra (EELS) were recorded to follow the structural and chemical changes during the reduction in $\mathrm{H}_{2}$.

Figure 1 (a-d) show the HREM images and associated $\mathrm{Ce} \mathrm{M}_{4,5}$ (white-lines) spectra from a $\mathrm{CeO}_{2}$ particle during the redox cycle; (a) before reduction at room temperature (RT), (b) $512^{\circ} \mathrm{C}$ and (c) $700^{\circ} \mathrm{C}$ and (d) after re-oxidation at room temperature. Significant changes in the relative intensity ratio of the Ce white-lines were not observed until $700^{\circ} \mathrm{C}$. At this temperature, $\mathrm{M}_{5} / \mathrm{M}_{4}$ intensity ratio changed from 0.66 (RT) to $\sim 0.71\left(700^{\circ} \mathrm{C}\right)$ indicating that a fraction of the $\mathrm{Ce}^{+4}$ species transformed to the $\mathrm{Ce}^{+3}$ oxidation state. However, at $500^{\circ} \mathrm{C}$ we observed the onset of structural transformation as a partially ordered sheet-like structure formed at the outer edges of the particle. EELS data from this layer showed the presence of cerium and oxygen only and an absence of carbon or other possible contaminants. At $700^{\circ} \mathrm{C}$ this layer was still present but was separated from a central core of crystalline ceria by an amorphous layer as the particle underwent reduction. The morphology of the particle continued to change as the material re-oxidized at room temperature with the $\mathrm{CeO}_{2}$ particle remaining in a highly disorder state although the sheet like morphology was no longer present. When the sample was cooled to room temperature the white-line ratio confirmed the re-oxidation of $\mathrm{Ce}^{+3}$ to $\mathrm{Ce}^{+4}$. We are investigating this phenomenon in more detail and will perform similar experiments on the $(\mathrm{Ce}, \mathrm{Zr}) \mathrm{O}_{2}$ systems. Results will be discussed in terms of the impact of different structural re-arrangements on redox properties.

\section{References}

[1] D.R. Mulins et al., Surf. Sci. 409 (1998)307. 
[2] R. Sharma et al., Phil. Mag. 84 (2004) 2731.

[3] Li et al., J. Solid State Chem. 168 (2002) 52.

[4] R. Sharma et al., Microsc. Microanal. (2003) CD314.

[5] The support from the National Science Foundation (NSF-CTS-0306688) and the use of TEM at the John M.Cowley Center for High Resolution Microscopy at Arizona State University are gratefully acknowledged.
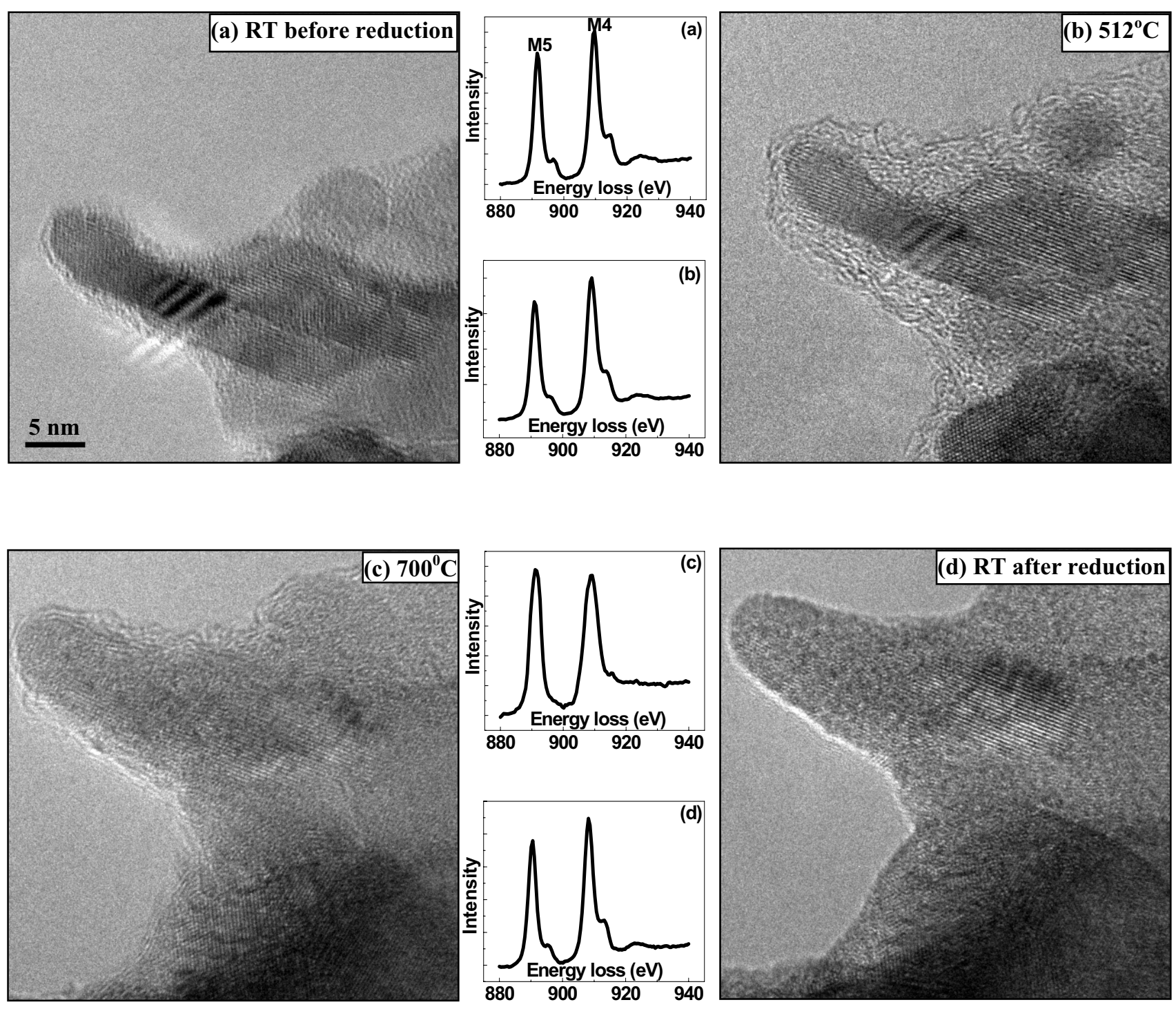

Fig.1. Time and temperature resolved HREM images and associated electron energy-loss spectra from high surface-area ceria sample recorded in 0.5 Torr of $25 \% \mathrm{H}_{2} / 75 \% \mathrm{~N}_{2}$ at (a) room temperature (before reduction), (b) $512^{\circ} \mathrm{C}$, (c) $700^{\circ} \mathrm{C}$ and (d) room temperature (re-oxidized). 